\title{
Profilometric changes of peri-implant tissues over 5 years: A randomized controlled trial comparing a one- and two-piece implant system
}

Sapata, Vitor Marques ; Sanz-Martín, Ignacio ; Hämmerle, Christoph H F ; César Neto, João B ; Jung, Ronald E ; Thoma, Daniel S

Abstract: OBJECTIVES To assess the profilometric changes of the buccal soft tissues between baseline and 5 years of loading using a one- and two-piece dental implant system. MATERIALS AND METHODS Sixty patients randomly received dental implants of either a two-piece type (BRA) or a one-piece type (STM). Casts were obtained at baseline (after crown insertion), at the 1-year and at the 5-year follow-up. Stereolithography files were obtained from the casts for digital superimposition. One implant and the contralateral natural tooth were selected for the analysis. Thirty-three patients $(\mathrm{BRA}=16$; STM $=17)$ were included. Measurements included changes for crown height $(\mathrm{CH})$ and estimated soft tissue thickness, as well as the profilometric change at the implant and the tooth site. Nonparametric methods were applied for the statistical analyses and medians and quartiles presented. RESULTS The BRA group lost $-0.39 \mathrm{~mm}$ and the STM group lost $-0.40 \mathrm{~mm}$ of volume between baseline and the 5 -year follow-up at the implant site $(\mathrm{p}>0.05)$. The tooth site lost $-0.18 \mathrm{~mm}$ (BRA) and $-0.12 \mathrm{~mm}(\mathrm{STM})(\mathrm{p}>$ 0.05 ). Volume differences between implants and teeth amounted to $-0.05 \mathrm{~mm}$ (baseline to 1 year) and $-0.25 \mathrm{~mm}$ (baseline to 5 years) for BRA, while for STM, the values were $0.03 \mathrm{~mm}$ (baseline to 1 year) and $-0.16 \mathrm{~mm}$ (baseline to 5 years). The changes for implant $\mathrm{CH}$ at 1 and 5 years of follow-up amounted 0.10 and $0.09 \mathrm{~mm}$ (BRA) and to 0.03 and $0.22 \mathrm{~mm}$ (STM). The changes in tissue thickness at 1 and 5 years in the BRA group amounted to -0.28 and $-0.66 \mathrm{~mm}$ at $1 \mathrm{~mm},-0.21$ and $-0.46 \mathrm{~mm}$ at $3 \mathrm{~mm}$, and -0.32 and $-0.45 \mathrm{~mm}$ at $5 \mathrm{~mm}$, respectively. The changes in the STM group amounted to -0.15 and $-0.54 \mathrm{~mm}$ at $1 \mathrm{~mm},-0.24$ and $-0.48 \mathrm{~mm}$ at $3 \mathrm{~mm}$, and -0.32 and $-0.57 \mathrm{~mm}$ at $5 \mathrm{~mm}$, respectively. No significantly different medians were observed. CONCLUSIONS Minimal profilometric and linear changes occurred at implant sites between baseline and 5 years, between implant and tooth sites and between the two implant systems.

DOI: https://doi.org/10.1111/clr.13308

Posted at the Zurich Open Repository and Archive, University of Zurich

ZORA URL: https://doi.org/10.5167/uzh-153076

Journal Article

Accepted Version

Originally published at:

Sapata, Vitor Marques; Sanz-Martín, Ignacio; Hämmerle, Christoph H F; César Neto, João B; Jung, Ronald E; Thoma, Daniel S (2018). Profilometric changes of peri-implant tissues over 5 years: A randomized controlled trial comparing a one- and two-piece implant system. Clinical Oral Implants Research, 29(8):864-872.

DOI: https://doi.org/10.1111/clr.13308 


\section{Profilometric changes of peri-implant tissues over 5 years: a randomized controlled trial comparing a one- and two-piece implant system}

Sapata $\mathrm{VM}^{1}{ }^{1}{ }^{2}$, Sanz-Martin $\mathrm{I}^{1}$, Hämmerle $\mathrm{CHF}^{1}$, César Neto $\mathrm{JB}^{2}$, Jung $\mathrm{RE}^{1}$, Thoma $\mathrm{DS}^{1}$

1 Clinic of Fixed and Removable Prosthodontics and Dental Material Science, University of Zurich, Zurich, Switzerland

2 Discipline of Periodontics, School of Dentistry, University of São Paulo, São Paulo, Brazil

Key words: crown, dental implants, denture, fixed, humans, partial, soft tissue, profilometric analysis.

Running title: 5-year profilometric changes of peri-implant tissues.

Address for correspondence:

Daniel S. Thoma, PD Dr. med. dent.

Clinic of Fixed and Removable Prosthodontics and Dental Material Science

University of Zurich

Plattenstrasse 11

$\mathrm{CH}-8032$ Zurich, Switzerland

Phone: +41446343257

Fax: +41446344305

e-mail: daniel.thoma@zzm.uzh.ch 


\section{Abstract}

Objectives: To assess the profilometric changes of the buccal soft tissues between baseline and five years of loading using a one- and two-piece dental implant system.

Materials and methods: Sixty patients randomly received dental implants of either a two-piece type (BRA) or a one-piece type (STM). Casts were obtained at baseline (after crown insertion), at the 1-year and at the 5-year follow-up. Stereolithography (STL) files were obtained from the casts for digital superimposition. One implant and the contralateral natural tooth were selected for the analysis. Thirtythree patients $(B R A=16 ; S T M=17)$ were included. Measurements included changes for crown height $(\mathrm{CH})$ and estimated soft tissue thickness (eTT), as well as the profilometric change (PC) at the implant and the tooth site. Nonparametric methods were applied for the statistical analyses and medians and quartiles presented.

Results: The BRA group lost $-0.39 \mathrm{~mm}$ and the STM group lost -0.40 $\mathrm{mm}$ of volume between baseline and the 5-year follow-up at the implant site $(p>0.05)$. The tooth site lost $-0.18 \mathrm{~mm}(B R A)$ and -0.12 mm (STM) $(p>0.05)$. Volume differences between implants and teeth amounted to $-0.05 \mathrm{~mm}$ (baseline to 1 year) and $-0.25 \mathrm{~mm}$ (baseline to 5 year) for BRA, while for STM, the values were $0.03 \mathrm{~mm}$ (baseline to 1 year) and $-0.16 \mathrm{~mm}$ (baseline to 5 year). The changes for implant 
crown height at 1 and 5 years of follow-up amounted $0.10 \mathrm{~mm}$ and $0.09 \mathrm{~mm}$ (BRA) and to $0.03 \mathrm{~mm}$ and $0.22 \mathrm{~mm}$ (STM). The changes in tissue thickness at 1 and 5 years in the BRA group amounted to -0.28 $\mathrm{mm}$ and $-0.66 \mathrm{~mm}$ at $1 \mathrm{~mm},-0.21 \mathrm{~mm}$ and $-0.46 \mathrm{~mm}$ at $3 \mathrm{~mm}$ and $0.32 \mathrm{~mm}$ and $-0.45 \mathrm{~mm}$ at $5 \mathrm{~mm}$ respectively. The changes in the STM group amounted to $-0.15 \mathrm{~mm}$ and $-0.54 \mathrm{~mm}$ at $1 \mathrm{~mm},-0.24 \mathrm{~mm}$ and $-0.48 \mathrm{~mm}$ at $3 \mathrm{~mm}$ and $-0.32 \mathrm{~mm}$ and $-0.57 \mathrm{~mm}$ at $5 \mathrm{~mm}$ respectively. No significantly different medians were observed.

Conclusions: Minimal profilometric and linear changes occurred at implant sites between baseline and 5 years, between implant and tooth sites and between the two implant systems. 


\section{Introduction}

Implant therapy is a predictable treatment modality with high survival rates on the implant and the restorative level (Jung et al. 2008; Pjetursson et al. 2012). From a clinical point of view, survival rates do not entirely reflect the outcomes of a specific therapy, since they lack complication rates. For that purpose, success criteria were defined in the past. These criteria included parameters such as continuous prosthesis stability, radiographic bone loss and absence of infection in the peri-implant soft tissues (Smith \& Zarb 1989; Albrektsson \& Zarb 1998; Misch et al. 2008).

In addition, the visual appearance of the treatment and the final prosthetic outcome became important parameters for clinical success. One of the goals is to create a harmony between the natural and the reconstructed dentition. For that purpose, soft tissue stability at the buccal aspect of implant reconstructions is important. In the past, various parameters, methods and measurements were used to evaluate the visual appearance, esthetics and soft tissue stability (Benic et al. 2012a). Recent clinical data assessed the relationship between the height of the buccal bone and the soft tissue stability (Benic et al. 2012b; Kuchler et al. 2016). It was concluded that the vertical bone dimension was associated with a reduction in width of the keratinized mucosa and a thin buccal bone wall (Kuchler et al. 2016). 
Moreover, a vertical resorption of the facial bone wall leads to an increased risk for soft tissue recession (Benic et al. 2012b). It was also demonstrated that the buccal soft tissues might compensate for buccal bone loss (Benic et al. 2012b). The analysis of clinical and profilometric changes of the buccal soft tissues might therefore serve as a valuable parameter to assess the outcomes of implant therapy. In order to assess volume changes of soft tissues, a non-invasive method was developed, further refined and applied for a variety of indications and studies (Windisch et al. 2007; Thoma et al. 2010; Schneider et al. 2011; Sanz Martin et al. 2016).

The primary objective of the present study was therefore to assess the profilometric changes of the buccal soft tissues between baseline and five years of loading using a one- and two-piece dental implant system. The null hypothesis of the present study was that the use of a one- and two-piece dental implant system results in equal median volume changes over an observation period from baseline to 5 years. 


\section{Materials and Methods}

Study design

The present study was designed as a randomized controlled clinical trial and approved by Kantonale Ethikkommission Zürich (KEKZH-Nr. 2014-0201). Sixty patients seeking dental implant therapy at the Clinic of Fixed and Removable Prosthodontics and Dental Material Science, Center of Dental Medicine, University of Zurich, Switzerland between the years 2002 and 2005 were consecutively included. A study monitor prepared a simple random allocation with sequentially numbered, opaque sealed envelopes, based on a computer-generated list. At the day of implant placement, the study monitor opened the envelopes assigning the patients to be treated with titanium dental implants of either a two-piece type (Brånemark system Mk III, TiUnite surface, Nobel Biocare, Zurich, Switzerland; BRA) or a one-piece type (Straumann Tissue Level, SLA surface, Institute Straumann, Basel, Switzerland; STM). Neither participants nor clinicians were blinded after enrollment. Patients were treated using the same clinical protocol. The only difference was the implant system placed, with the surgeon deciding to take a submerged or transmucoal approach healing mode. The majority of the implants were left submerged. The following inclusion criteria was applied: medically healthy condition and older than 18 years. Patients with local contraindications such as 
systemic medical conditions, drug abuse, or local jaw pathology were excluded. The original study was designed with a follow-up period of 5 years with interim reports scheduled at 1 year. No changes were made after the initiation of the study. The sample size was calculated based on a previous publication including 28 partially edentulous patients, but with a split-mouth design (Astrand et al. 2002). Therefore, the number of included patients was increased to 60 (30 per group) (Thoma et al. 2014). For the present data reporting on profilometric changes of the peri-implant tissues, more specific inclusion/exclusion criteria were applied. Inclusion criteria were: fixed reconstructions, implant sites in the anterior zone of the maxilla/mandible (including premolars, but excluding molars), available casts for all time points (baseline, one year, five years) and no artefacts on the included casts. Patients and sites not meeting all inclusion criteria were excluded from the present analysis. The present study is in compliance with the CONSORT Statement.

\section{Model fabrication}

Alginate impressions (Hydrogum 5, Zhermack, Padoua, Italy) at the baseline examination (day of loading), at one year and at five years were taken and dental stone type IV (GC Fujirock EP, GC Europe, Leuven, Belgium) casts were fabricated. Both materials, alginate and dental stone, were fabricated according the manufacturer instructions 
by an automatic device. The trays were carefully selected for each patient according to the region of interest for all impressions. Models with the presence of irregularities such as porous areas, undefined gingival margins, broken cusps, or undefined vestibulum were excluded.

Stereolithography image acquisition and matching of data

A desktop 3D scanner (Imetric 3D, Courgenay, Switzerland) optically scanned the selected cast models. STereoLithography (STL) files from Baseline, 1-year and 5-year were uploaded to an image analysis software (Swissmeda Software; Swissmeda AG, Zurich, Switzerland) and superimposed automatically by the program. Then, a manual fine alignment was performed using the implant crown (rigid structure) as reference between time points (Fig. 1a).

Profilometric and image analysis

In case patients had received more than one dental implant at implant placement surgery, just one of these was randomly chosen for the profilometric analysis according to a computer-generated randomization list. All other implants were not evaluated for profilometric changes in the present study. Moreover, the contralateral natural tooth, or its adjacent, was selected for the analysis. A calibrated (k:0.93), blinded evaluator, with access just to the STL files on the image analysis software, without any kind of identification of 
the groups and patients, performed all the measurements twice, with an interval of 7 days. The following measurements at baseline, 1-year and 5-year follow-up in previously randomly selected sites were assessed:

(i) Linear measurements: A longitudinal slice divided the crown mesio-distally equally. In the transversal images of the sections, a line coinciding with the axis of the tooth was drawn. To measure the dimension of the clinical crown $(\mathrm{CH})$ changes the distance between two lines perpendicular to the axis of the tooth coinciding with the most prominent cusp and the gingival margin was assessed. To evaluate the estimated soft tissue thickness (eTT) changes, a line perpendicular to the axis of the tooth was drawn. The distance between this line and buccal soft outline was then assessed at 1,3 , and $5 \mathrm{~mm}$ below the gingival margin (Fig. 1b).

(ii) Profilometric measurements: The software calculated the profilometric change (PC: mean distance between the surfaces in $\mathrm{mm}$ ) considering the area bordered by the mucosal margin at the analyzed site (mesial and distal line angles and extended 3-6 mm apically) (Fig. 1c \& 1d).

Radiographic measurements

A paralleling technique with Rinn-holders using analog films (Kodak Ektaspeed plus; Eastman Kodak CO, Rochester, NY, USA) was 
used to take intraoral radiographs of implants at all time points. All radiographs were digitized. An open-source software (Image J; National Institutes of Health, Bethesda, MD, USA) was used to analyze the marginal bone levels. To calibrate the measurements, the known distance between the implant threads (BRA: $0.6 \mathrm{~mm}$; STM: $1.25 \mathrm{~mm}$ ) were used. To assess the marginal bone level, the mesial and distal implant surfaces were measured considering the distance from the reference point (BRA: flat top of the implant, STM: implant shoulder). The distance between the implant shoulder and the marginal bone level (DIB) were calculated.

Statistical analysis

For data description, mean and standard deviation, median and quartiles for metric were calculated. The median and quartiles are described in the text and all these measures are given in the tables. For the comparison of two group medians one applied nonparametric tests because of the small sample sizes; either the Wilcoxon signed rank test was used for dependent groups or the Mann-Whitney test for independent groups. The assumptions (symmetry or distribution with equal shape) of these tests were checked only qualitatively (with scatter plots) in the applications because of the small sample sizes. The significance level was set at $5 \%$. The primary endpoint is the profilometric change change from baseline to 5-year follow-up. For this 
primary endpoint nonparametric $95 \%$ confidence intervals are derived. All the other parameters are considered as secondary endpoints. For these corresponding tests no correction of the multiple testing is used. In addition, it was investigated whether further explanatory factors (e.g. minor bone augmentation - dehiscence or fenestration defectsat implant placement) might explain the different group means or medians with parametric or nonparametric ANOVA models. 


\section{Results}

Sixty prosthetic reconstructions were placed (BRA: 30 patients, STM: 30 patients) supported by 151 implants (BRA: 86 implants, STM: 65 implants). Out of this patient pool, patient with fixed reconstructions (BRA: 29 patients, STM: 26 patients) were able to participate in the study (Fig. $2 \& 3$ ). After model examination, 33 patients were enrolled (BRA: 16 patients, STM: 17 patients) and 99 casts were selected for profilometric analysis. All the casts models (99) and periapical radiographs (99) from the 33 patients enrolled were analyzed. The profilometric and radiographic analysis were performed by a calibrated examiner, not involved in the clinical procedures. Only the profilometric analysis could be performed in a blinded way.

Out of 33 patients enrolled, 26 (BRA: 12 patients, STM: 14) received guided bone regeneration (GBR) procedures (Bio-Gide, Geistlich Pharma AG, Wolhusen, Switzerland; Bio-Oss, Geistlich Pharma AG, Wolhusen, Switzerland) at implant placement to treat dehiscence defects (height: 1 to $5 \mathrm{~mm}$ ) and apical fenestrations. Nonparametric comparison was used to analyze the four subgroups (STM with GBR; STM without GBR; BRA with GBR; BRA without GBR). A statistically significant difference between groups was found only at $\mathrm{DIB}_{\mathrm{BL} / \mathrm{FU}-5}(p=0.0445)$ and at $\mathrm{DIB}_{\mathrm{BL} / \mathrm{FU}-1}(0.0504)$. When the post-hoc test (Bonferroni) was performed, only DIB $\mathrm{BL}_{\mathrm{BFU}-1}$ between STM with GBR 
vs. BRA without GBR showed a statistically significant difference $(p=0.0471)$.

\section{Profilometric changes, linear measurements and radiographic parameters between Baseline and 5-year follow up (FU-5)}

The volume changes on the buccal side of implants (IPC $C_{B L / F U-5)}$ revealed a loss of $0.39(-0.62 ;-0.28) \mathrm{mm}(\mathrm{BRA})$ and of $-0.40(-0.58 ;-$ 0.26) $\mathrm{mm}(\mathrm{STM})$. The medians are not significantly different, $p=0.7320$. The $95 \%$ confidence interval for the median difference of the two groups is $(-0.13,0.22)$, which is completely within the bounds

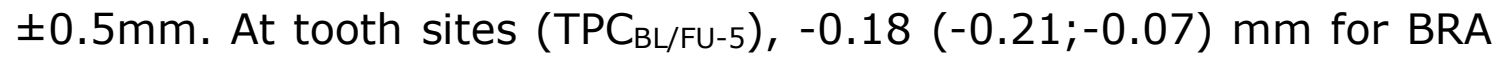
and $-0.12(-0.19 ;-0.03) \mathrm{mm}$ for STM were lost over 5 years. Further outcomes measures are given in Table 1.

For implant sites, the crown height change $\left(\mathrm{ICH}_{\mathrm{BL} / \mathrm{FU}-5}\right)$ increased $0.09(-0.10 ; 0.50) \mathrm{mm}$ for BRA and $0.22(-0.18 ; 0.48) \mathrm{mm}$ for STM. For tooth sites, the crown height changes $\left(\mathrm{TCH}_{\mathrm{BL} / \mathrm{FU}-5)}\right)$ increased 0.13 ($0.27 ; 0.41) \mathrm{mm}$ for BRA and $0.03(-0.16 ; 0.35) \mathrm{mm}$ for STM.

The changes for the estimated soft tissue thickness at implant sites (IeTT $\mathrm{BL} / \mathrm{FU}-5)$ and tooth sites (TeTT $\mathrm{BL} / \mathrm{FU}-5)$ can be found in Table 1.

The DIB $_{B L / F U-5}$ were $1.41(1.09 ; 1.61) \mathrm{mm}$ (BRA) and 0.50 $(0.16 ; 0.61) \mathrm{mm}(\mathrm{STM})$.

There were no statistically significant different medians found 
between BRA and STM for the profilometric changes, linear measurements (Table 1) and radiographic parameters (Table 4).

Profilometric changes, linear measurements, and radiographic parameters between Baseline (BL) and the 1-year follow-up (FU-1)

The volume changes at implant sites (IPC $\mathrm{BL}_{\mathrm{BF}-1}$ ) revealed a loss of $-0.16(-0.26 ;-0.11) \mathrm{mm}($ BRA $)$ and of $-0.07(-0.23 ; 0.01) \mathrm{mm}(\mathrm{STM})$. The medians were not significantly different $(p=0.2056)$. The respective changes at the contralateral tooth sites ( $\left(\mathrm{TPC}_{\mathrm{BL} / \mathrm{FU}-1)}\right.$ amounted to $-0.11(-0.14 ;-0.08) \mathrm{mm}(\mathrm{BRA})$ and $-0.10(-0.15 ;-0.04)$ $\mathrm{mm}$ (STM).

For implant sites, the crown height change $\left(\mathrm{ICH}_{\mathrm{BL} / \mathrm{FU}-1}\right)$ increased $0.10(-0.14 ; 0.23) \mathrm{mm}$ for BRA and $0.03(-0.04 ; 0.17) \mathrm{mm}$ for STM. For tooth sites, the crown height changes $\left(\mathrm{TCH}_{\mathrm{BL} / \mathrm{FU}-1)}\right)$ increased 0.04 ($0.24 ; 0.20) \mathrm{mm}$ for BRA and $0.02(-0.5 ; 0.14) \mathrm{mm}$ for STM.

The changes for the estimated soft tissue thickness at implant ( $\operatorname{IeTT}_{\mathrm{BL} / \mathrm{FU}-1}$ ) and tooth sites (TeTT $\left.\mathrm{BL} / \mathrm{FU}-1\right)$ can be found in Table 2.

The changes in distance between the implant shoulder and the marginal bone level $\left(\mathrm{DIB}_{\mathrm{BL} / \mathrm{FU}-1}\right)$ were $1.17(0.67 ; 1.28) \mathrm{mm}(\mathrm{BRA})$ and $0.43(0.07 ; 1.02) \mathrm{mm}(\mathrm{STM})$.

There were no statistically significant different medians found 
between BRA and STM for the profilometric changes, linear measurements and radiographic parameters (Table 2).

\section{Profilometric changes between tooth and implant site}

The volume differences between implants and teeth from baseline to the 1-year follow-up were $-0.05(-0.18 ; 0.00) \mathrm{mm}$ for BRA and $0.03(-0.20 ; 0.10) \mathrm{mm}$ for STM with a $95 \%$ confidence interval for the different medians $(-0.11,0.2)(p=0.3747)$. From baseline to the $5-$ year follow-up, the differences were $-0.25(-0.46 ;-0.05) \mathrm{mm}$ for BRA and $-0.16(-0.57 ;-0.11) \mathrm{mm}$ for STM with a $95 \%$ confidence interval for the different medians $(-0.17,0.22)(p=0,9282)$. There were no statistically significant different medians found between BRA and STM for these comparisons (Table 3). 


\section{Discussion}

Comparing one- and two-piece dental implant systems minimal changes were observed in terms of implant crown height, estimated soft tissue thickness and the profilometric changes at the buccal side of implants and contralateral teeth during a 5-year observation period. Moreover, no significantly different medians were observed between tooth and implant sites.

The differences in implant crown height between the one- and two-piece implants were minimal $(0.07 \mathrm{~mm})$ at 1 year of follow-up, with both groups showing minimal recession of the soft tissues (BRA: $0.10 \mathrm{~mm}$; STM: $0.03 \mathrm{~mm}$ ). At 5 years of follow-up, the loss of soft tissue was $0.09 \mathrm{~mm}$ for BRA and $0.22 \mathrm{~mm}$ for STM. The recession rate can be considered clinically stable, without changes on the BRA group and a recession rate of $0.05 \mathrm{~mm} /$ year for STM. In comparison, two studies with one-piece dental implants showed similar results in terms of recession (Blanes et al. 2007; Gallucci et al. 2011). Based on this earlier long-term clinical study, a recession depth of $0.15( \pm 0.54) \mathrm{mm}$ at the one-year follow-up and of $0.33( \pm 0.7) \mathrm{mm}$ at 6 years was measured. This translates into a yearly loss of approximately $0.04 \mathrm{~mm}$ (Blanes et al. 2007). In the more recent study, a small recession at crown insertion was found, but then stable results at 1 and 2 years of follow-up (Gallucci et al. 2011). The outcomes of the present study also 
indicate that in order to assess small changes of the soft tissues over time, digital methods might be more easily applicable (Schneider et al. 2011) and with optimal accuracy (Windisch et al. 2007) compared to previous more invasive techniques (periodontal probes or endodontic files).

It has been reported previously that over time, peri-implant tissue undergoes remodeling processes. This is based on changes at the hard tissue and the soft tissue level (Benic et al. 2012b; Kuchler et al. 2016). In both studies one-piece dental implants were used. It was concluded that the buccal bone height was associated with a reduction in width of the keratinized mucosa, a thin buccal bone wall (Kuchler et al. 2016) and an increased risk for soft tissue recession (Benic et al. $2012 \mathrm{~b}$ ). In the present study, linear measurements assessing the buccal tissues thickness at implant sites revealed only minor changes over 5 years. Moreover, the analyses comparing the two implant system, did not demonstrate any clinically relevant differences. The literature is scarce for any other clinical studies evaluating long term tissue changes at the buccal aspect of implants. The data based on the profilometric analysis corroborate with the findings of the linear measurements. At the one-year follow-up, the BRA group lost $0.09 \mathrm{~mm}$ $(-0.16 \mathrm{~mm})$ more volume compared to the STM group $(-0.07 \mathrm{~mm})$. Up to 5-year follow-up, the BRA group demonstrated a contraction rate of 
$-0.06 \mathrm{~mm} /$ year compared to $-0.08 \mathrm{~mm} /$ year of STM group, leading to a very similar volume at the 5 -year follow-up. In a prospective clinical study (Jemt \& Lekholm 2005), the long-term profilometric changes after bone grafting and single two-piece implant treatment were evaluated. All patients showed an average volume reduction during the first year, and a stable situation during the following 4 years, with individuals' variations. This is in line with the outcomes of the present study, demonstrating more loss of volume during the first year then thereafter. The method of analysis was, however, slightly different.

A previous study utilizing three-dimensional imaging analysis (Jung et al. 2015) reported vertical bone stability after 5 years of evaluation. In the present study the radiographic analysis evaluated the distance from implant shoulder to marginal bone level (DIB). The bone loss on the first year was greater compared to the following years. At 5 years of follow-up, the BRA group lost $0.06 \mathrm{~mm} /$ year with a loss of $1.17 \mathrm{~mm}$ on the first year, and the STM group lost $0.02 \mathrm{~mm} /$ year after a loss of $0.43 \mathrm{~mm}$ on the first year, resulting in three times more bone loss around the implant in the BRA group compared to the STM group (BRA: $1.41 \mathrm{~mm}$ vs. STM: $0.50 \mathrm{~mm}$ ). Although, both groups demonstrated interproximal vertical bone stability, the observed difference could be associated with the design and surface roughness differences between the two groups (BRA: TiUnite vs. STM: SLA). 
However, neither a clear positive nor negative relationship was found between DIB values and profilometric outcomes. This might be due to bone augmentation procedures, various locations and the peri-implant soft tissues that compensates for the observed marginal bone loss (Benic et al. 2012b).

In order to evaluate the clinical relevance of the calculated linear and profilometric changes at implant sites, similar measurements were performed at contralateral tooth sites and compared with both implant groups. At the one-year follow-up, the BRA group lost 0.05 $\mathrm{mm}$ (profilometric outcomes) compared to the natural tooth sites, and the STM group lost $0.03 \mathrm{~mm}$ compared to natural teeth. Between the 1- and 5-year follow-up, greater changes at implant than at tooth sites were observed with implants demonstrating a higher volume loss. However, the analysis did not reveal any statistically significant different means between implant and tooth sites.

Clinically, the study presented very similar results between BRA and STM group specially on a long term evaluation. Even when compared to the natural tooth, the implant sites corresponded well and lost around $0.2 \mathrm{~mm}$ more volume compared to the natural tooth sites. This amount of volume loss could be considered clinically irrelevant and barely hard to assess.

The use of alginate to take the impressions can be considered a 
limitation of this study. Although the impressions were poured into stone immediately after they were taken, the inferiority of this material compared to a silicon or a polyether based impression material is obvious and might have led to less models available for analysis, due to the inability to re-fabricate the dental stone cast. This might have also affected the sample size, which decreased after model selection, resulting in 33 patients included, compared to the initial sample of 60 patients (a few cases with removable prostheses had to be additionally excluded). Further limitations included that neither clinicians, nor patients nor the examiner performing the analysis of the peri-apical radiographs were blinded. Future research should focus on an even longer follow-up applying similar outcome measures and potentially including patient-reported outcome measures. 


\section{Conclusions}

Minimal profilometric and linear changes occurred at implant sites during 5 years of follow-up. The comparison between teeth and implants demonstrated slightly more volume loss at implant site without statistical significance. The differences in profilometric and linear changes over time were negligible between the one- and the two-piece dental implant system. Inter-individual and inter-site differences, however, exhibited an extended range for profilometric and linear outcome measures. 


\section{Acknowledgements and conflict of interest}

The authors would like to acknowledge Prof. Dr. Jürg Hüsler for his support in the statistical analysis of the data. This study was funded by the Clinic of Fixed and Removable Prosthodontics and Dental Material Science, Center of Dental Medicine, University of Zurich, Zurich, Switzerland. The authors report no conflict of interest for this study. 


\section{REFERENCES:}

Albrektsson T. \& Zarb G.A. (1998) Determinants of correct clinical reporting. The International Journal of Prosthodontics 11: 517-521.

Åstrand P., Engquist B., Anzén B., Bergendal T., Hallman M., Karlsson U., et al. (2002) Nonsubmerged and submerged implants in the treatment of the partially edentulous maxilla. Clinical implant dentistry and related research 4: 115-127.

Benic G.I., Wolleb K., Sancho-Puchades M. \& Hämmerle C.H.F. (2012a) Systematic review of parameters and methods for the professional assessment of aesthetics in dental implant research. Journal of Clinical Periodontology 39: 160-192.

Benic G.I., Mokti M., Chen C.-J., Weber H.-P., Hämmerle C.H.F. \& Gallucci G.O. (2012b) Dimensions of buccal bone and mucosa at immediately placed implants after 7 years: a clinical and cone beam computed tomography study. Clinical Oral Implants Research 23: $560-566$.

Blanes R.J., Bernard J.P., Blanes Z.M. \& Belser U.C. (2007) A 10-year prospective study of ITI dental implants placed in the posterior region. I: Clinical and radiographic results. Clinical Oral Implants Research 18: 699-706.

Gallucci G.O., Grütter L., Chuang S.-K. \& Belser U.C. (2011) 
Dimensional changes of peri-implant soft tissue over 2 years with single-implant crowns in the anterior maxilla: Peri-implant soft-tissue dimensions with different implant crowns. Journal of Clinical Periodontology 38: 293-299.

Jemt T. \& Lekholm U. (2005) Single Implants and Buccal Bone Grafts in the Anterior Maxilla: Measurements of Buccal Crestal Contours in a 6-Year Prospective Clinical Study. Clinical implant dentistry and related research 7: 127-135.

Jung R.E., Benic G.I., Scherrer D. \& Hämmerle C.H.F. (2015) Cone beam computed tomography evaluation of regenerated buccal bone 5 years after simultaneous implant placement and guided bone regeneration procedures - a randomized, controlled clinical trial. Clinical Oral Implants Research 26: 28-34.

Jung R.E., Pjetursson B.E., Glauser R., Zembic A., Zwahlen M. \& Lang N.P. (2008) A systematic review of the 5-year survival and complication rates of implant-supported single crowns. Clinical Oral Implants Research 19: 119-130.

Kuchler U., Chappuis V., Gruber R., Lang N.P. \& Salvi G.E. (2016) Immediate implant placement with simultaneous guided bone regeneration in the esthetic zone: 10 -year clinical and radiographic outcomes. Clinical Oral Implants Research 27: 253-257. 
Misch C.E., Perel M.L., Wang H.-L., Sammartino G., Galindo-Moreno P., Trisi P., et al. (2008) Implant Success, Survival, and Failure: The International Congress of Oral Implantologists (ICOI) Pisa Consensus Conference: Implant Dentistry 17: 5-15.

Pjetursson B.E., Thoma D., Jung R., Zwahlen M. \& Zembic A. (2012) A systematic review of the survival and complication rates of implantsupported fixed dental prostheses (FDPs) after a mean observation period of at least 5 years. Clinical Oral Implants Research 23: 22-38. Sanz Martin I., Benic G.I., Hämmerle C.H.F. \& Thoma D.S. (2016) Prospective randomized controlled clinical study comparing two dental implant types: volumetric soft tissue changes at 1 year of loading. Clinical Oral Implants Research 27: 406-411.

Schneider D., Grunder U., Ender A., Hämmerle C.H.F. \& Jung R.E. (2011) Volume gain and stability of peri-implant tissue following bone and soft tissue augmentation: 1-year results from a prospective cohort study: Volume gain and stability of peri-implant tissue following bone and soft tissue augmentation. Clinical Oral Implants Research 22: 2837.

Smith D.E. \& Zarb G.A. (1989) Criteria for success of osseointegrated endosseous implants. The Journal of Prosthetic Dentistry 62: 567572. 
Thoma D.S., Jung R.E., Schneider D., Cochran D.L., Ender A., Jones A.A., et al. (2010) Soft tissue volume augmentation by the use of collagen-based matrices: a volumetric analysis: Soft tissue volume augmentation. Journal of Clinical Periodontology 37: 659-666.

Thoma D.S., Sanz Martin I., Benic G.I., Roos M. \& Hämmerle C.H.F. (2014) Prospective randomized controlled clinical study comparing two dental implant systems: demographic and radiographic results at one year of loading. Clinical Oral Implants Research 25: 142-149.

Windisch S.I., Jung R.E., Sailer I., Studer S.P., Ender A. \& Hämmerle C.H.F. (2007) A new optical method to evaluate three-dimensional volume changes of alveolar contours: a methodological in vitro study. Clinical Oral Implants Research 18: 545-551. 


\section{Figure Legends}

Fig. 1 - (a) Superimposition of STereoLithography (STL) models. Baseline (yellow), 1-year follow-up (gray) and 5-year follow-up (green). Red line indicating central section. (b) Outline of baseline (yellow), 1-year follow-up (gray) and 5-year follow-up (green) models and linear measurements performed in central section. $\mathrm{CH}$, clinical crown height; eTT1, estimated tissue thickness at $1 \mathrm{~mm}$ below the mucosal/gingival margin, eTT3, estimated tissue thickness at $3 \mathrm{~mm}$ below the mucosal/gingival margin, eTT5, tissue thickness at $5 \mathrm{~mm}$ below the mucosal/gingival margin. (c) Superimposed STereoLithography (STL) models with colored area (blue) representing the analyzed area (PC: mean distance between the surfaces in $\mathrm{mm}$ ) from the implant site. (d) Superimposed STereoLithography (STL) models with colored area (black) representing the analyzed area (PC: mean distance between the surfaces in $\mathrm{mm}$ ) from the contralateral natural tooth.

Fig. 2 - Clinical comparison between time points (a) at baseline, (b) 1year follow-up, (c) 5-year follow-up for implant 41 (BRA), and (d) baseline, (e) 1-year follow-up, (f) 5-year follow-up for implant 35 (STM).

Fig. 3 - Radiographical comparison between time points (a) at baseline,

(b) 1-year follow-up, (c) 5-year follow-up for implant 41 (BRA), and 
(d) baseline, (e) 1-year follow-up, (f) 5-year follow-up for implant 35 (STM). 


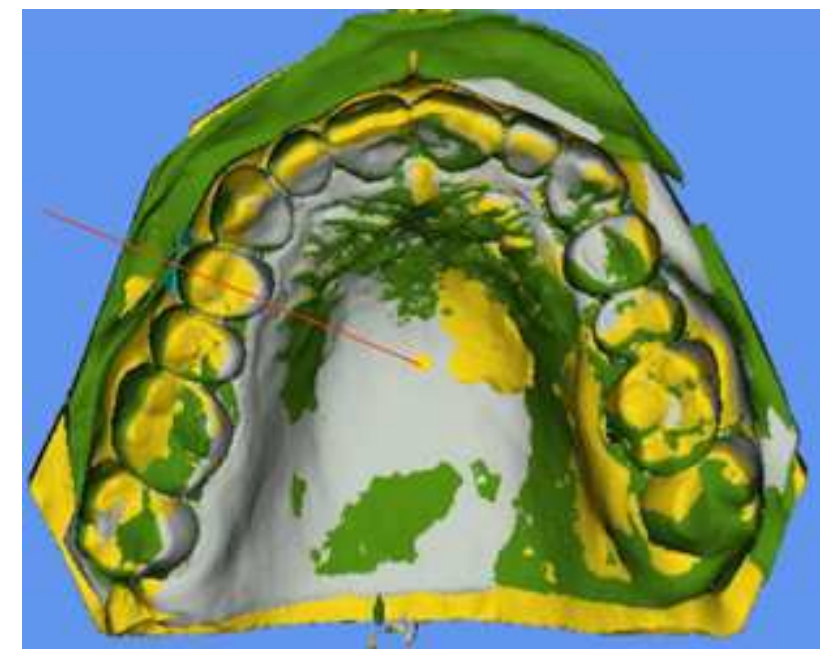

Fig. 1a

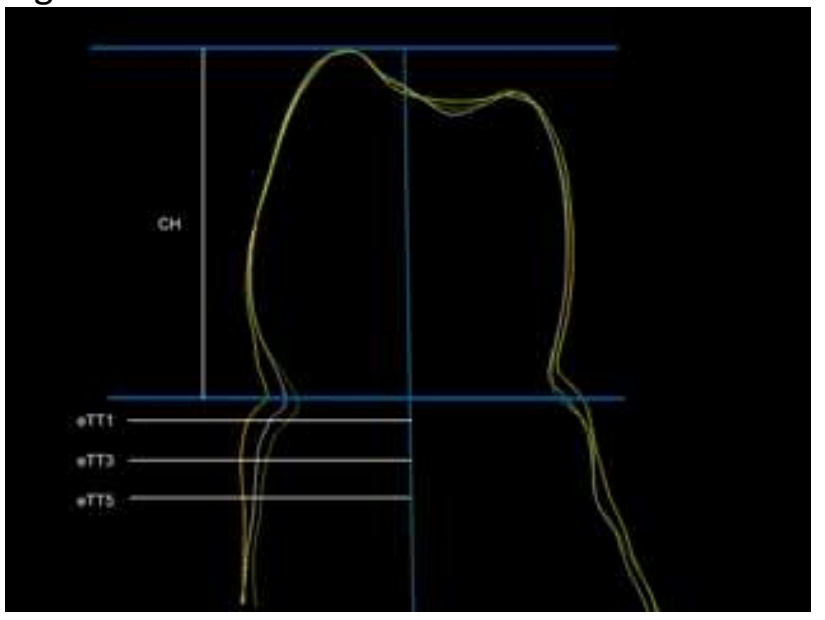

Fig. 1b

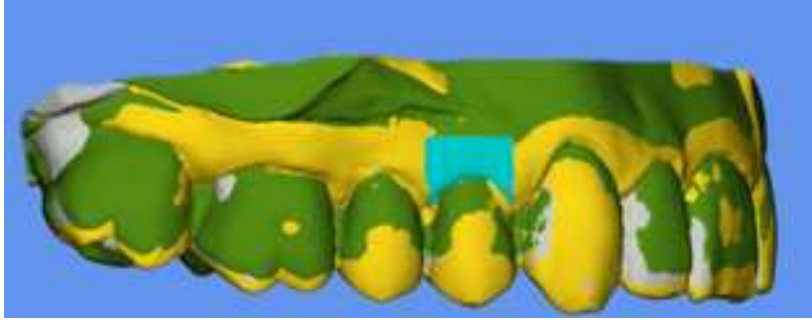

Fig. 1c

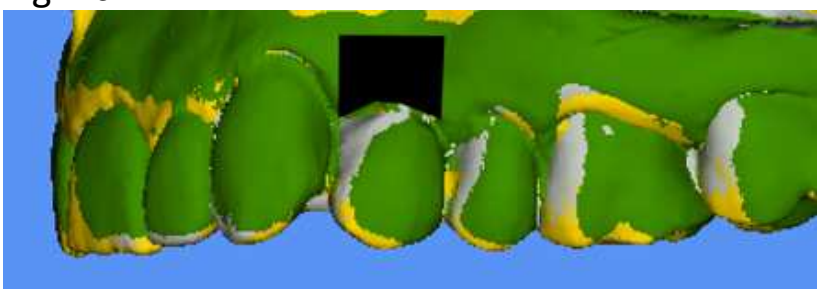

Fig. 1d 


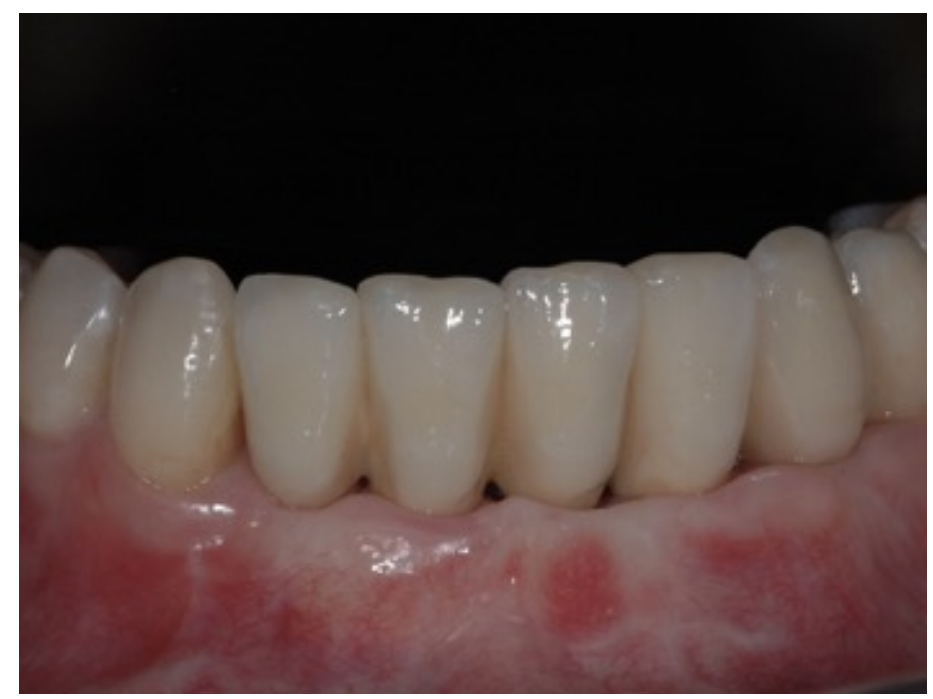

Fig. 2a

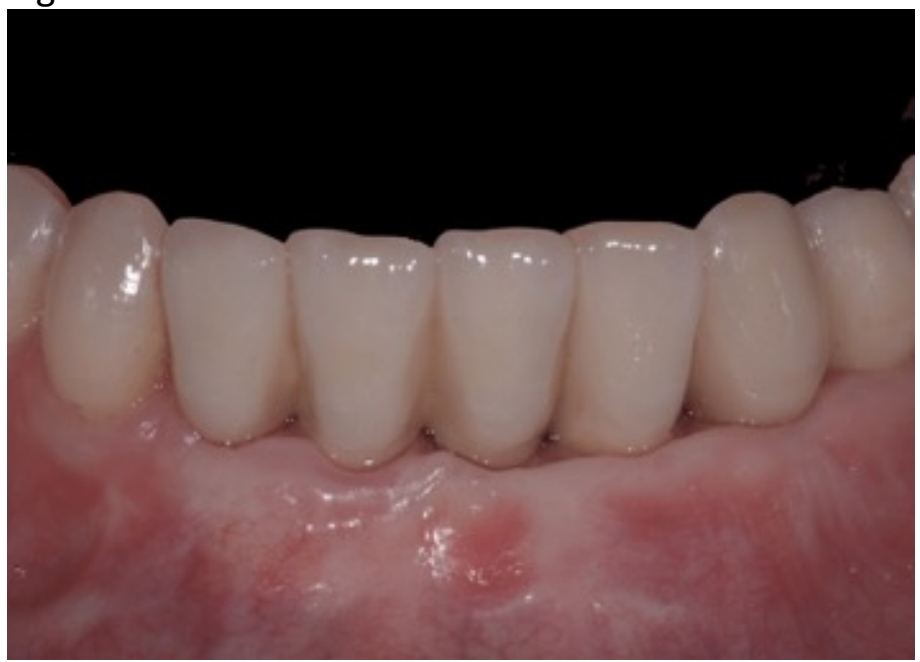

Fig. $2 b$

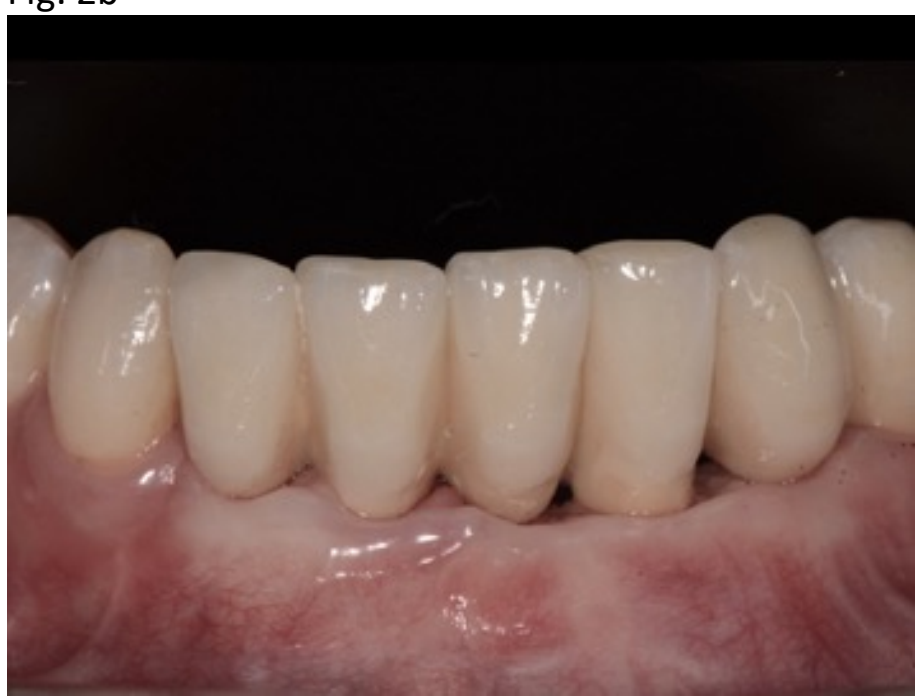

Fig. 2c 


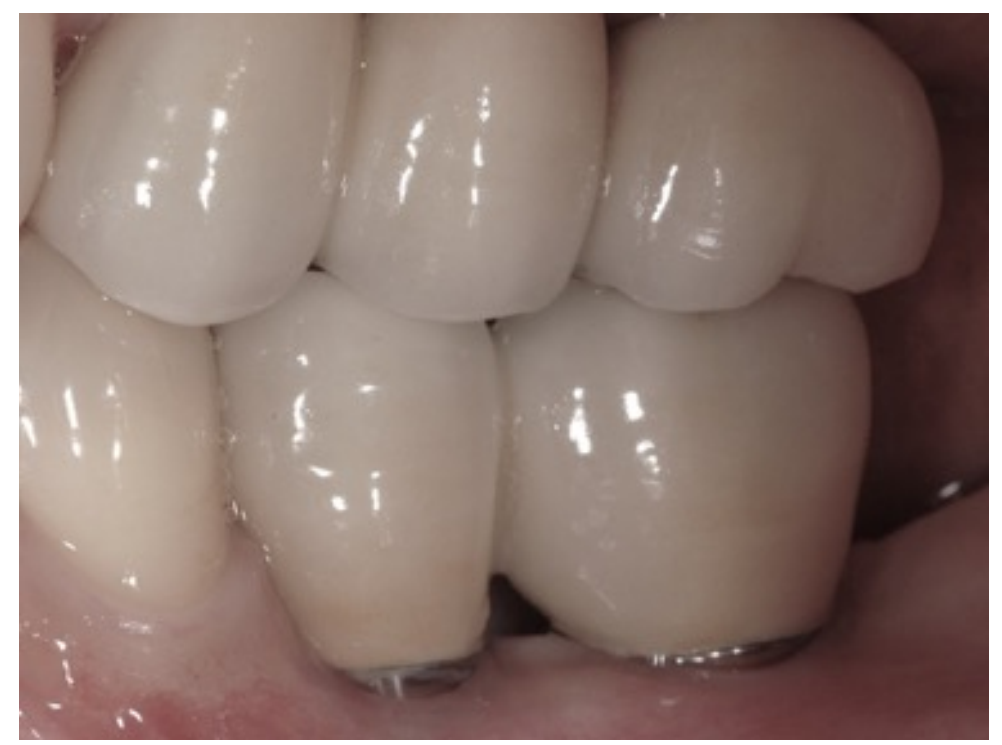

Fig. 2d

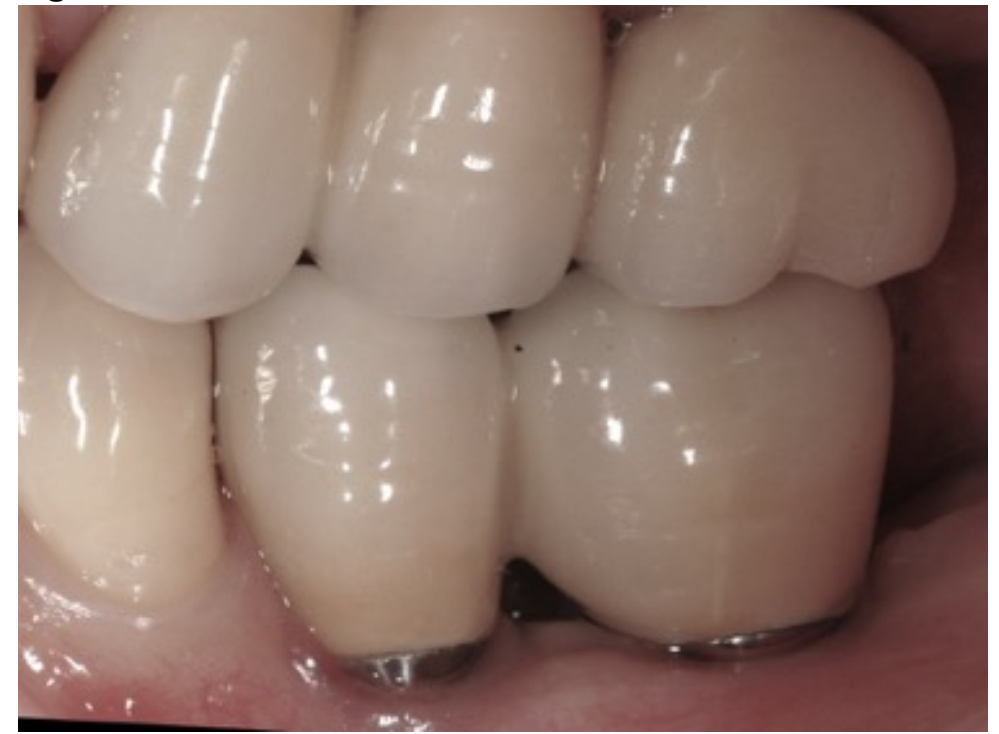

Fig. 2e

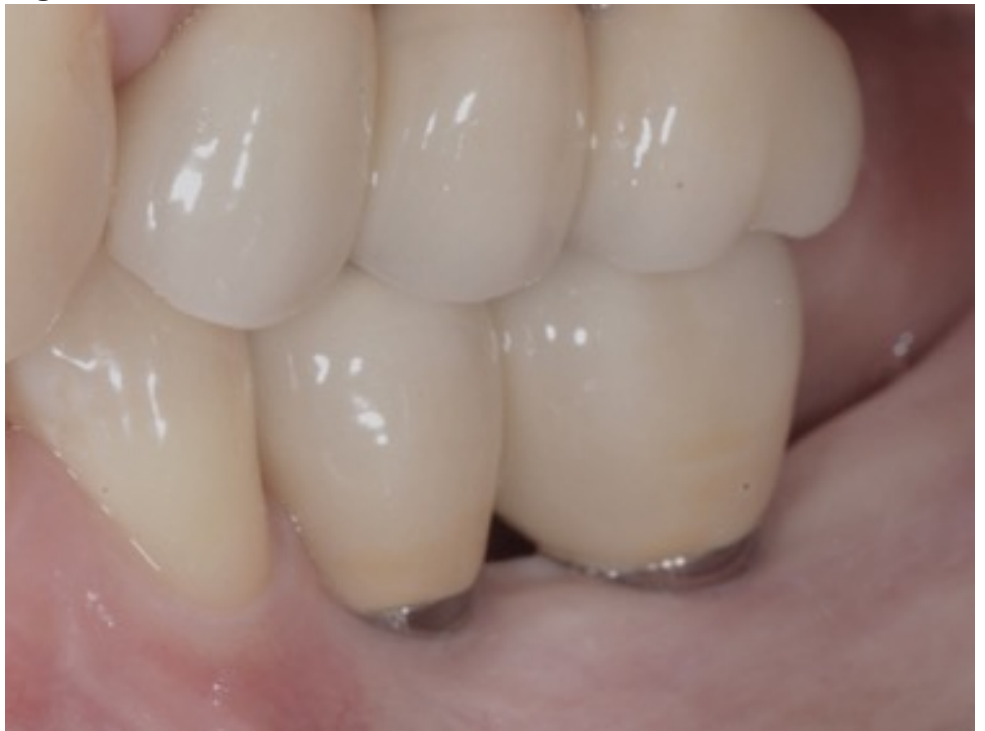

Fig. $2 f$ 


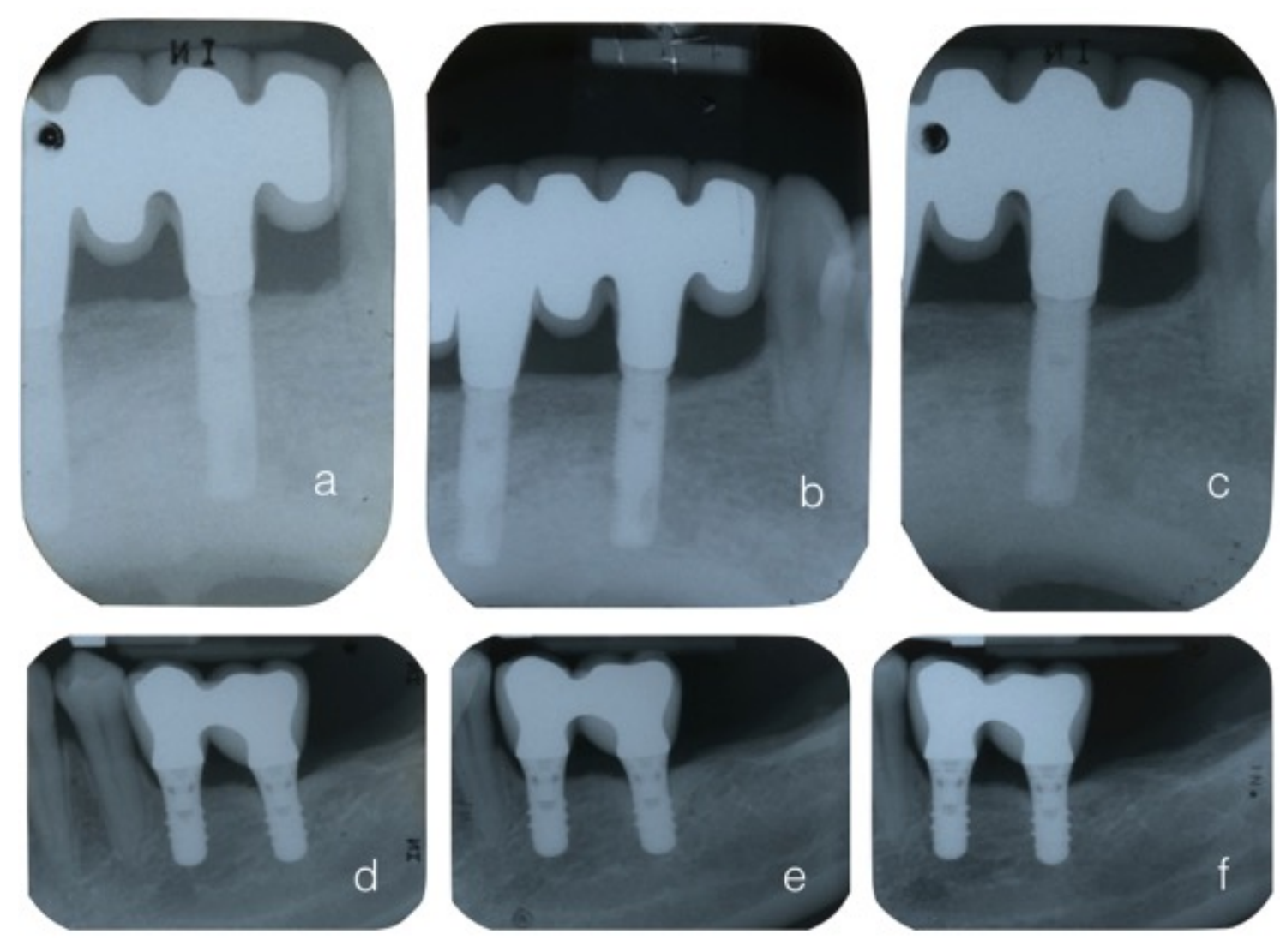

Fig. 3 
Table 1. Changes between baseline and 5-year follow-up in linear measurements, profilometric measurements and radiographic parameters

\begin{tabular}{|c|c|c|}
\hline Variables in mm (means and SD/median and quartile) & BRA & STM \\
\hline Implant crown height (ICHBL/FU-5) & $0.23(0.43) / 0.09(-0.10 ; 0.50)$ & $0.35(0.73) / 0.22(-0.18 ; 0.48)$ \\
\hline Implant profilometric changes (IPC & $-0.45(0.47) /-0.39(-0.62 ;-0.28)$ & $-0.48(0.33) /-0.40(-0.58 ;-0.26)$ \\
\hline Implant estimated soft tissue thickness at $1 \mathrm{~mm}$ (IеTT1 & $-0.72(0.51) /-0.66(-0.83 ;-0.47)$ & $-0.63(0.46)-0.54(-0.79 ;-0.29)$ \\
\hline Implant estimated soft tissue thickness at $3 \mathrm{~mm}$ (ІеТТЗВц/FU-5) & $-0.53(0.37) /-0.46(-0.51 ;-0.34)$ & $-0.56(0.43) /-0.48(-0.78 ;-0.34)$ \\
\hline Implant estimated soft tissue thickness at $5 \mathrm{~mm}$ (IeTT5 & $-0.60(0.52) /-0.45(-0.66 ;-0.42)$ & $-0.53(0.64) /-0.57(-0.87 ;-0.19)$ \\
\hline Distance from implant shoulder to marginal bone level (DIBBL/FU-5) & $1.34(0.45) / 1.41(1.09 ; 1.61)$ & $0.44(0.42) / 0.50(0.16 ; 0.61)$ \\
\hline Tooth crown height (TCHвLFu-5) & $0.08(0.51) / 0.13(-0.27 ; 0.41)$ & $0.11(0.34) / 0.03(-0.16 ; 0.35)$ \\
\hline Tooth profilometric changes (TPC & $-0.15(0.09) /-0.18(-0.21 ;-0.07)$ & $-0.13(0.13) /-0.12(-0.19 ;-0.03)$ \\
\hline Tooth estimated soft tissue thickness at $1 \mathrm{~mm}$ (TeTT1 1 BL/FU-5) & $-0.28(0.10) /-0.27(-0.34 ;-0.20)$ & $-0.22(0.18) /-0.21(-0.38 ;-0.13)$ \\
\hline Tooth estimated soft tissue thickness at $3 \mathrm{~mm}$ (ТеTTЗвц/Fu-5) & $-0.44(1.25) /-0.14(-0.22 ;-0.11)$ & $-0.16(0.20) /-0.13(-0.27 ;-0.03)$ \\
\hline Tooth estimated soft tissue thickness at $5 \mathrm{~mm}$ (ТеTТ5вц/Fu-5) & $-0.10(0.20) /-0.10(-0.24 ; 0.06)$ & $0.16(0.83) /-0.12(-0.26 ; 0.16)$ \\
\hline
\end{tabular}


Table 2. Changes between baseline and 1-year follow-up in linear measurements, profilometric measurements and radiographic parameters

\begin{tabular}{|c|c|c|}
\hline Variables in mm (means and SD/median and quartile) & BRA & STM \\
\hline Implant crown height (ICHBL/FU-1) & $0.06(0.34) / 0.10(-0.14 ; 0.23)$ & $0.05(0.41) / 0.03(-0.04 ; 0.17)$ \\
\hline Implant profilometric changes (IPC & $-0.18(0.19) /-0.16(-0.26 ;-0.11)$ & $-0.08(0.28) /-0.07(-0.23 ; 0.01)$ \\
\hline Implant estimated soft tissue thickness at $1 \mathrm{~mm}$ (IеTT1 $1 \mathrm{BL/FU-1})$ & $-0.27(0.19) /-0.28(-0.36 ;-0.16)$ & $-0.22(0.45) /-0.15(-0.27 ;-0.01)$ \\
\hline Implant estimated soft tissue thickness at $3 \mathrm{~mm}$ (ІеТТЗВв/FU-1) & $-0.25(0.24) /-0.21(-0.25 ;-0.11)$ & $-0.14(0.41) /-0.24(-0.38 ;-0.01)$ \\
\hline Implant estimated soft tissue thickness at $5 \mathrm{~mm}$ (ІеTT5вц/Fu-1) & $-0.33(0.32) /-0.32(-0.34 ;-0.23)$ & $-0.17(0.57) /-0.32(-0.53 ; 0.26)$ \\
\hline Distance from implant shoulder to marginal bone level (DIBвL/FU-1) & $1.01(0.50) / 1.17(0.67 ; 1.28)$ & $0.56(0.54) / 0.43(0.07 ; 1.02)$ \\
\hline Tooth crown height (TCHBLFU-1) & $-0.12(0.60) / 0.04(-0.24 ; 0.20)$ & $0.09(0.28) / 0.02(-0.5 ; 0.14)$ \\
\hline Tooth profilometric changes (TPC & $-0.10(0.07) /-0.11(-0.14 ;-0.08)$ & $-0.08(0.09) /-0.10(-0.15 ;-0.04)$ \\
\hline Tooth estimated soft tissue thickness at $1 \mathrm{~mm}$ (TeTT1 $1 \mathrm{BLFU}-1)$ & $-0.17(0.13) /-0.19(-0.22 ;-0.11)$ & $-0.11(0.13) /-0.08(-0.14 ;-0.03)$ \\
\hline Tooth estimated soft tissue thickness at $3 \mathrm{~mm}$ (ТеTTЗВц/FU-1) & $-0.19(0.27) /-0.11(-0.18 ;-0.09)$ & $-0.08(0.12) /-0.06(-0.14 ;-0.02)$ \\
\hline Tooth estimated soft tissue thickness at $5 \mathrm{~mm}$ (TeTT5 & $-0.07(0.26) /-0.18(-0.24 ; 0.22)$ & $0.21(0.78) /-0.01(-0.12 ; 0.12)$ \\
\hline
\end{tabular}




\begin{tabular}{ccc}
\hline Table 3. Comparison between implant and tooth in profilometric measurements & Baseline / 5 Year \\
\hline Variables in mm (means and SD/median and quartile) & Baseline / 1 Year & $-0.30(0.47) /-0.25(-0.46 ;-0.05)$ \\
BRA - contralateral tooth & $-0.08(0.21) /-0.05(-0.18 ; 0.00)$ & $-0.34(0.36) /-0.16(-0.57 ;-0.11)$ \\
STM - contralateral tooth & $0.00(0.26) / 0.03(-0.20 ; 0.10)$ & 0,9282 \\
Significance & 0,3747 & \\
\hline SD, standard deviation. * $P<0.05$. & & \\
\hline
\end{tabular}




\section{Table 4. Radiographic comparison between implant sites with or without guided bone regeneration (GBR)}

\begin{tabular}{ccccc}
\hline Variables in mm (means and & BRA with GBR $(\mathrm{n}=12)$ & BRA without GBR $(\mathrm{n}=4)$ & STM with GBR (n=14) & STM without GBR (n=3) \\
SD/median and quartile) & & & \\
Changes in DIB (mm) - BL/FU1 & $0.07(0.27) /-0.02(-0.11 ; 0.20)$ & $-0.02(0.12) /-0.01(-0.12 ; 0.08) *$ & $0.36(0.34) / 0.23(0.17 ; 0.55) *$ & $0.16(0.53) / 0.02(-0.30 ; 0.74)$ \\
Changes in DIB (mm) - BL/FU5 & $0.41(0.41) / 0.44(0.17 ; 0.67)$ & $0.27(0.31) / 0.26(0.02 ; 0.51)$ & $0.15(0.51) / 0.09(-0.22 ; 0.41)$ & $0.47(0.73) / 0.23(-0.11 ; 1.29)$ \\
Changes in DIB (mm) - FU1/FU5 & $0.34(0.43) / 0.37(0.21 ; 0.58)$ & $0.29(0.36) / 0.18(0.03 ; 0.54)$ & $-0.21(0.47) /-0.30(-0.59 ; 0.19)$ & $0.32(0.89) / 0.19(-0.51 ; 1.27)$ \\
\hline
\end{tabular}

SD, standard deviation; DIB, distance between implant shoulder and marginal bone level; BL, baseline; FU1, 1-year follow-up; FU5, 5year follow-up; ${ }^{*}=0,0471$ between groups (Bonferroni correction) 